\title{
Erratum zu: Migration und Bildungsarmut: Übertrittsrisiken im Schweizer Bildungssystem
}

\author{
Michael Beck und Franziska Jäpel
}

\section{Erratum zu: \\ Kapitel „Migration und Bildungsarmut: Übertrittsrisiken im Schweizer Bildungssystem" in: G. Quenzel und K. Hurrelmann (Hrsg.), Handbuch Bildungsarmut, https://doi.org/10.1007/978-3-658-19573-1_19}

Das Kapitel Migration und Bildungsarmut: Übertrittsrisiken im Schweizer Bildungssystem, wurde ursprünglich am 13-Aug-2018 elektronisch auf SpringerLink ohne Open Access veröffentlicht.

Mit der Entscheidung des Autors, Open Access zu nutzen, wurde das Copyright des Kapitels am 7-Feb-2019 in (C Der/die Autor(en) 2019 geändert. Das Kapitel wird künftig unter der Creative Commons Namensnennung 4.0 International Lizenz (http://creativecommons. org/licenses/by/4.0/deed.de) veröffentlicht, welche die Nutzung, Vervielfältigung, Bearbeitung, Verbreitung und Wiedergabe in jeglichem Medium und Format erlaubt, sofern Sie den/ die ursprünglichen Autor(en) und die Quelle ordnungsgemäß nennen, einen Link zur Creative Commons Lizenz beifügen und angeben, ob Änderungen vorgenommen wurden. Die in diesem Kapitel enthaltenen Bilder und sonstiges Drittmaterial unterliegen ebenfalls der genannten Creative Commons Lizenz, sofern sich aus der Abbildungslegende nichts anderes ergibt. Sofern das betreffende Material nicht unter der genannten Creative Commons Lizenz steht und die betreffende Handlung nicht nach gesetzlichen Vorschriften erlaubt ist, ist für die oben aufgeführten Weiterverwendungen des Materials die Einwilligung des jeweiligen Rechteinhabers einzuholen. 